\title{
Assessment of Factors Affecting Quality of Life in Oral Squamous Cell Carcinoma Patients Using University of Washington Quality of Life Questionnaire
}

Syed Abbas ${ }^{1}$, Muhammad Usman U. Tariq ${ }^{2}$, Ahmed Raheem ${ }^{2}$, Javeria Saeed ${ }^{3}$, Syed S. Hashmi ${ }^{4}$, Musa Karim ${ }^{5}$, Mazhar Nizam ${ }^{6}$

1. Otolaryngology, Aga Khan University Hospital, Karachi, PAK 2. Pathology, Aga Khan University Hospital, Karachi, PAK 3. Otolaryngology, Patel Hospital, Karachi, PAK 4. Otolaryngology, Baqai Medical University, Karachi, PAK 5. Miscellaneous, National Institute of Cardiovascular Diseases, Karachi, PAK 6. Plastic Surgery, Patel Hospital, Karachi, PAK

Corresponding author: Muhammad Usman U. Tariq, muhammadusmantariq84@gmail.com

\section{Abstract \\ Introduction}

Post-treatment Quality of Life (QOL) is considered an important outcome in cancer patients. A number of questionnaire tools have been designed for its assessment. University of Washington Quality of Life (UW QOL) questionnaire version four is a reliable tool for assessment of post-treatment QOL in oral squamous cell carcinoma (OSCC) patients. Our aim was to identify the post-treatment problems faced by OSCC patients and to assess the impact of clinical factors affecting post-treatment QOL by using UW QOL (version four) questionnaire.

\section{Methods}

The study was conducted on 59 patients with OSCC who were treated with curative intent at Patel Hospital, Karachi from August 2015 to September 2015. Patients were asked to fill the UW QOL questionnaire (version four) on their follow-up visit.

\section{Results}

Overall mean composite QOL score was $66.59 \pm 16.98$. Chewing and saliva (dryness of mouth) had the lowest scores (38.98 \pm 37.2 and $56.78 \pm 41.4$, respectively) among all domains while pain and anxiety had the highest scores ( $80.93 \pm 20.4$ and $79.66 \pm 29.8$, respectively). Patients having tumors of the tongue, late stage (III and IV) tumors, and restricted mouth opening had significantly lower mean composite QOL scores. Patients with tongue tumors revealed significantly lower scores for pain, swallowing, mood, and anxiety. Patients with late-stage tumors showed significantly lower scores for chewing, swallowing, taste, saliva, appearance,

Received 12/26/2018

Review began 12/30/2018 Review ended 01/08/2019 Published 01/16/2019

๑) Copyright 2019

Abbas et al. This is an open access article distributed under the terms of the Creative Commons Attribution License CC-BY 3.0., which permits unrestricted use, distribution, and reproduction in any medium, provided the original author and source are credited. anxiety, and recreation. Patients with restricted mouth opening had significantly lower scores for pain, speech, appearance, recreation, and anxiety domains.

\section{Conclusion}

Different clinical features have different impacts on QOL in terms of problems faced by the patients. Features having a significant effect should be identified, and measures focused on most relevant problems should be employed in order to improve the post-treatment QOL.

Categories: Otolaryngology, Plastic Surgery, Oncology

Keywords: oral, squamous cell carcinoma, post-treatment, quality of life, score

\section{Introduction}

Oral squamous cell carcinoma (OSCC) is a leading cause of cancer-related morbidity and mortality with the global annual incidence approaching 500,000 [1]. Annual OSCC incidence in Pakistan is 14,000 and urban Karachi has one of the highest incidences of OSCC worldwide [2]. Approximately 50\% of these patients present with advanced stage (III or IV) disease and this translates into poor outcomes in survival pattern and the five-year survival rate is $20 \%$ [3]. Those who survive have varying degrees of compromised quality of life (QOL) [4]. Radiation to head and neck region has long-term implications such as limited mouth opening and dryness in the oral cavity [5]. The combined effect is significantly compromised speech and swallowing ability culminating in poor nutritional status and inability to return to a fully functional lifestyle.

There is a dire need to understand the functional limitations of these patients as a result of the disease process and subsequent interventions [6]. Significant evidence exists in favor of QOL as a predictor of cancer 
survivorship among OSCC patients [7]. Hence, disease-free survival (DFS) and improved QOL are now considered as combined endpoints in these patients. The last decade has witnessed intense focus on OSCC survivors and much effort has been put to identify the factors affecting the QOL. This would help in implementing therapies and measures aimed at improving the outcome.

Various QOL questionnaires have been used to estimate the outcomes in OSCC. University of Washington Quality of Life (UW QOL) questionnaire version four is a simple, brief and well-validated questionnaire that is globally employed in OSCC patients [8]. The incorporation of two important psychosocial factors (mood and anxiety) has made it a comprehensive tool to assess the outcome [9].

There is a paucity of literature from South Asia regarding QOL where OSCC is virtually endemic. This particular study aims at addressing the factors affecting post-treatment QOL in OSCC patients from a tertiary care hospital of Karachi, Pakistan. So far, no study has evaluated post-treatment QOL using the UW QOL questionnaire in Pakistani population. Identification of such possible prognosticators may help us start specific therapies aimed at improving the outcomes in these patients.

\section{Materials And Methods}

This cross-sectional study was conducted at our Patel Hospital, Karachi from August 2015 to September 2015. This study was approved by the hospital's ethics committee (approval number: 44). A total of 120 patients with biopsy-proven OSSC were treated at our department during this period. Patients who underwent surgical excision with or without radiotherapy and/or chemotherapy with curative intent were included in the study. Patients treated with palliative intent and those treated with chemotherapy alone or chemoradiotherapy without surgery were excluded. Fifty-nine patients were finally selected in the study.

UW QOL questionnaire (Version 4) was employed as the questionnaire tool which is a self-reporting 12 point scale addressing pain, appearance, activity, recreation, swallowing, chewing, speech, shoulder function, taste, saliva, mood, and anxiety [10]. It also takes into consideration the most important issues faced by the patient over the last seven days. The responses from patients were rated from 0 (worst) to 100 (best) and mean scores for an individual was calculated. Patients with a higher mean score were interpreted to have a good outcome in terms of QOL.

In addition, there are two questions which address the patient's perception about his/her well-being. These are Health Related QOL (HR-QOL) and Global QOL (G-QOL). HR-QOL assesses the overall health perception of the patient over the last seven days, while G-QOL assesses the overall QOL of the patient over the last seven days. These responses are scored on a 6 point Likert scale (ranging from very poor to outstanding). This purpose of the study was explained to the patients during their follow-up visit. Written informed consent was obtained from the patients. They were asked to fill out the questionnaire in a separate room and they were helped in filling out their responses where required.

Demographic and treatment-related details were obtained from the head and neck cancer database maintained at our department. The UW-QOL questionnaire related data was entered and analyzed using IBM SPSS Statistics for Windows, Version 21.0. (IBM Corp., Armonk, NY, US). The descriptive statistics were calculated for demographic variables in terms of mean \pm SD. Patients were divided into two age groups $(\leqslant 47$ years and $>47$ years) based on median age, i.e., 47 years. Frequency and percentages were calculated for all categorical variables. Overall mean composite scores of QOL, HR-QOL, and G-QOL were calculated by using multiple response analysis. Seven factors were assessed for their impact on QOL in our patients. These include patient's age, pre-operative oral addiction habits, restricted mouth opening, tumor site, tumor stage, treatment modality and follow up duration. The two-tailed analysis was conducted by applying the MannWhitney U test and Kruskal Wallis test to check the significance of the difference in mean QOL scores of each domain in different groups. The $p$-value of less than 0.05 was considered significant.

\section{Results}

Patient's age ranged from 22 to 70 years with a mean \pm SD of $47.9 \pm 12.7$ years. Male to female ratio was 1.36:1. The follow-up duration ranged from six to seventy-three months with a mean \pm SD of $33.4 \pm 19.6$ months. Overall mean composite QOL score was $66.59 \pm 16.98$. Chewing and saliva had the lowest scores among all domains while pain and anxiety had the highest scores (Figure 1). 


\section{Cureus}

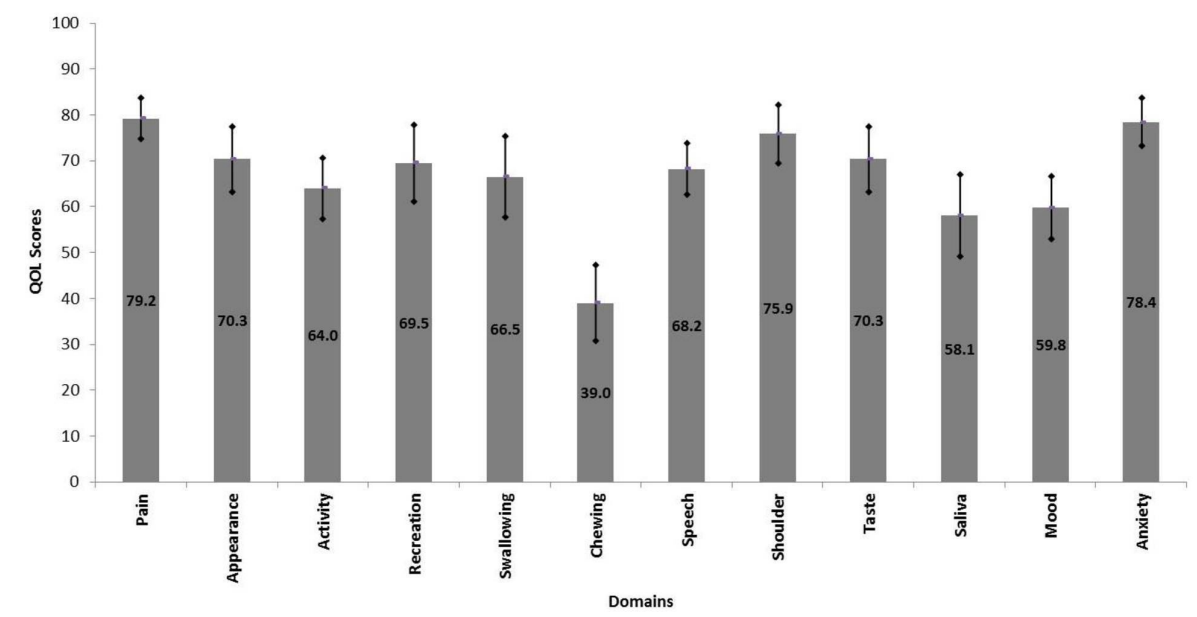

FIGURE 1: Mean quality of life scores of different domains in all patients.

Patients having tumors of a tongue, late stage (III and IV) tumors, and restricted mouth opening had significantly lower mean composite QOL scores when compared with patients having tumors of cheek, early stage (I and II) tumors, and normal mouth opening, respectively. Females, older patients (> 47 years), patients without oral addiction habits and without co-morbid also had lower mean composite QOL scores when compared with patients males, older patients, (> 47 years), patients with oral addiction habits and with co-morbid, respectively. But the difference was statistically insignificant. Patients with single modality treatment had best mean composite QOL scores and there was a linear drop in QOL scores as the number of treatment modalities increased but statistical significance was not observed (Table 1). 


\section{Cureus}

\begin{tabular}{|c|c|c|c|}
\hline Characteristics & Frequency (\%) & Composite Score [Mean \pm SD] & p-value \\
\hline \multicolumn{4}{|l|}{ Gender } \\
\hline Male & $34(57.63 \%)$ & $68.01 \pm 16.71$ & \multirow{2}{*}{0.438} \\
\hline Female & $25(42.37 \%)$ & $64.67 \pm 17.51$ & \\
\hline \multicolumn{4}{|l|}{ Age } \\
\hline Up to 47 years & $30(50.85 \%)$ & $68.26 \pm 11.98$ & \multirow{2}{*}{0.676} \\
\hline More than 47 years & $29(49.15 \%)$ & $64.87 \pm 21.04$ & \\
\hline \multicolumn{4}{|l|}{ Oral addiction habits } \\
\hline Yes & 46 (77.97\%) & $67.89 \pm 16.81$ & \multirow{2}{*}{0.309} \\
\hline No & $13(22.03 \%)$ & $62.02 \pm 17.48$ & \\
\hline \multicolumn{4}{|l|}{ Co-morbids } \\
\hline Yes & $15(25.42 \%)$ & $70.42 \pm 22.96$ & \multirow{2}{*}{0.143} \\
\hline No & $44(74.58 \%)$ & $65.29 \pm 14.51$ & \\
\hline \multicolumn{4}{|l|}{ Tumor site } \\
\hline Tongue (anterior 2/3) & $29(49.15 \%)$ & $62.14 \pm 15.31$ & \multirow{2}{*}{$0.029^{\star}$} \\
\hline Cheek & $30(50.85 \%)$ & $70.9 \pm 17.65$ & \\
\hline \multicolumn{4}{|l|}{ Tumor stage } \\
\hline Early Stage (I and II) & $27(45.76 \%)$ & $74.38 \pm 11.67$ & \multirow{2}{*}{$0.002^{\star}$} \\
\hline Late Stage (III and IV) & 32 (54.24\%) & $60.02 \pm 18.11$ & \\
\hline \multicolumn{4}{|l|}{ Mouth opening } \\
\hline Within normal limits & $17(28.81 \%)$ & $75.61 \pm 15.93$ & \multirow{2}{*}{$0.003^{*}$} \\
\hline Restricted mouth opening & $42(71.19 \%)$ & $62.95 \pm 16.17$ & \\
\hline \multicolumn{4}{|l|}{ Treatment modality } \\
\hline Surgery & 10 (16.95\%) & $71.46 \pm 15.44$ & \multirow{3}{*}{0.148} \\
\hline Surgery and radiotherapy & $46(77.97 \%)$ & $66.8 \pm 16.67$ & \\
\hline Surgery, radio and chemotherapy & $3(5.08 \%)$ & $47.22 \pm 18.9$ & \\
\hline \multicolumn{4}{|l|}{ Follow up duration } \\
\hline Up to 1 year & $8(13.6 \%)$ & $57.29 \pm 19.2$ & \multirow{3}{*}{0.244} \\
\hline 1 to 2 years & $17(28.8 \%)$ & $67.15 \pm 15.99$ & \\
\hline More than 2 years & $34(57.6 \%)$ & $68.5 \pm 16.7$ & \\
\hline
\end{tabular}

TABLE 1: Comparison of Quality of Life Composite Score by Patient Characteristics

When patients with cheek tumors were compared with the patients having tongue tumors, domain-wise comparison revealed significantly lower QOL scores for pain, swallowing, mood, and anxiety (Table 2). 


\section{Cureus}

\begin{tabular}{|c|c|c|c|}
\hline Domain & Anterior 2/3 Tongue $(n=29)[$ Mean $\pm S D]$ & Cheek $(n=30)[$ Mean \pm SD] & p-value \\
\hline Pain & $72.41 \pm 13.93$ & $85.83 \pm 18.2$ & $0.002^{\star}$ \\
\hline Appearance & $69.83 \pm 27.04$ & $70.83 \pm 29.42$ & 0.788 \\
\hline Activity & $62.07 \pm 25.55$ & $65.83 \pm 26.65$ & 0.571 \\
\hline Recreation & $66.38 \pm 32.92$ & $72.5 \pm 32.4$ & 0.436 \\
\hline Swallowing & $58.62 \pm 32.92$ & $74.17 \pm 34.42$ & $0.029^{\star}$ \\
\hline Chewing & $39.66 \pm 30.99$ & $38.33 \pm 33.95$ & 0.826 \\
\hline Speech & $62.93 \pm 27.24$ & $73.33 \pm 14.58$ & 0.137 \\
\hline Shoulder & $72.41 \pm 25.31$ & $79.17 \pm 24.64$ & 0.236 \\
\hline Taste & $65.52 \pm 27.88$ & $75 \pm 27.07$ & 0.122 \\
\hline Saliva & $53.45 \pm 33.22$ & $62.5 \pm 36.99$ & 0.215 \\
\hline Mood & $49.14 \pm 24.53$ & $70 \pm 24.91$ & $0.002^{*}$ \\
\hline Anxiety & $73.28 \pm 18.82$ & $83.33 \pm 21.1$ & $0.019^{\star}$ \\
\hline
\end{tabular}

TABLE 2: Comparison of Quality of Life Domains by Tumor Site

Patients with late-stage tumors showed significantly lower QOL scores for chewing, swallowing, taste, saliva, appearance, anxiety, and recreation, as compared to patients with early-stage tumors (Table 3).

\begin{tabular}{|c|c|c|c|}
\hline Domain & Early Stage $(n=27)$ [Mean \pm SD] & Late Stage $(n=33)$ [Mean \pm SD] & $p$-value \\
\hline Pain & $82.41 \pm 16.72$ & $76.56 \pm 17.89$ & 0.206 \\
\hline Appearance & $78.7 \pm 26.59$ & $63.28 \pm 27.67$ & $0.023^{\star}$ \\
\hline Activity & $68.52 \pm 23.61$ & $60.16 \pm 27.58$ & 0.221 \\
\hline Recreation & $78.7 \pm 31.55$ & $61.72 \pm 31.74$ & $0.026^{x}$ \\
\hline Swallowing & $83.33 \pm 21.93$ & $52.34 \pm 36.68$ & $0.001^{*}$ \\
\hline Chewing & $50 \pm 24.02$ & $29.69 \pm 35.6$ & $0.008^{\star}$ \\
\hline Speech & $74.07 \pm 12.94$ & $63.28 \pm 26.93$ & 0.089 \\
\hline Shoulder & $80.56 \pm 20.02$ & $71.88 \pm 28.22$ & 0.305 \\
\hline Taste & $77.78 \pm 25.32$ & $64.06 \pm 28.35$ & $0.045^{\star}$ \\
\hline Saliva & $69.44 \pm 29.69$ & $48.44 \pm 36.99$ & $0.036^{\star}$ \\
\hline Mood & $64.81 \pm 28.81$ & $55.47 \pm 24.37$ & 0.149 \\
\hline Anxiety & $84.26 \pm 18.54$ & $73.44 \pm 21$ & $0.037^{\star}$ \\
\hline
\end{tabular}

TABLE 3: Comparison of Quality of Life Domains by Tumor Stage

In comparison to patients with normal mouth opening, patients with restricted mouth opening had significantly lower scores for pain, speech, appearance, recreation, and anxiety domains (Table 4). 


\section{Cureus}

\begin{tabular}{|c|c|c|c|}
\hline Domain & Within Normal Limits $(n=17)$ [Mean \pm SD] & Restricted Mouth Opening $(n=42)[$ Mean \pm SD] & p-value \\
\hline Pain & $88.24 \pm 15.61$ & $75.6 \pm 17.01$ & $0.01^{*}$ \\
\hline Appearance & $86.76 \pm 17.94$ & $63.69 \pm 28.8$ & $0.004^{\star}$ \\
\hline Activity & $69.12 \pm 28.68$ & $61.9 \pm 24.84$ & 0.385 \\
\hline Recreation & $86.76 \pm 25.18$ & $62.5 \pm 32.78$ & $0.004^{\star}$ \\
\hline Swallowing & $72.06 \pm 34.1$ & $64.29 \pm 34.55$ & 0.374 \\
\hline Chewing & $52.94 \pm 37.38$ & $33.33 \pm 28.51$ & 0.052 \\
\hline Speech & $80.88 \pm 20.78$ & $63.1 \pm 20.83$ & $0.004^{\star}$ \\
\hline Shoulder & $80.88 \pm 27.29$ & $73.81 \pm 24.04$ & 0.152 \\
\hline Taste & $64.71 \pm 36.51$ & $72.62 \pm 23.3$ & 0.670 \\
\hline Saliva & $66.18 \pm 37.44$ & $54.76 \pm 34.14$ & 0.190 \\
\hline Mood & $70.59 \pm 25.36$ & $55.36 \pm 26.21$ & $0.043^{\star}$ \\
\hline Anxiety & $88.24 \pm 15.61$ & $74.4 \pm 21.02$ & $0.013^{\star}$ \\
\hline
\end{tabular}

TABLE 4: Comparison of Quality of Life Domains by Status of Mouth Opening

Interestingly, patients without pre-operative oral addiction habits showed significantly lower QOL scores for activity $(48.08 \pm 16.01$ versus $72.28 \pm 26.99)$ and recreation $(57.69 \pm 35.92$ versus $78.26 \pm 31.89)$ domains $(p-$ value: 0.004 and 0.044 , respectively).

When assessed for effect of the number of treatment modalities received by the patients, there was a decrease in mean scores of almost all domains but statistical significance was observed for anxiety domain only ( $p$-value: 0.004 ) (Table 5).

\begin{tabular}{|c|c|c|c|c|}
\hline Domain & $\begin{array}{l}\text { Surgery Alone }[n=10] \\
{[\text { Mean } \pm \text { SD] }}\end{array}$ & $\begin{array}{l}\text { Surgery and Radiotherapy [ }=46] \\
{[\text { Mean } \pm \text { SD] }}\end{array}$ & $\begin{array}{l}\text { Surgery, Radio and Chemotherapy [ }= \\
\text { 3] [Mean } \pm \text { SD] }\end{array}$ & $\begin{array}{l}\mathrm{p}- \\
\text { value }\end{array}$ \\
\hline Pain & $82.5 \pm 16.87$ & $78.8 \pm 18.23$ & $75 \pm 0$ & 0.764 \\
\hline Appearance & $72.5 \pm 21.89$ & $71.2 \pm 29.33$ & $50 \pm 25$ & 0.439 \\
\hline Activity & $67.5 \pm 23.72$ & $64.67 \pm 26.65$ & $41.67 \pm 14.43$ & 0.301 \\
\hline Recreation & $55 \pm 34.96$ & $74.46 \pm 30.95$ & $41.67 \pm 28.87$ & 0.070 \\
\hline Swallowing & $72.5 \pm 34.26$ & $66.85 \pm 34.18$ & $41.67 \pm 38.19$ & 0.397 \\
\hline Chewing & $50 \pm 33.33$ & $38.04 \pm 31.95$ & $16.67 \pm 28.87$ & 0.271 \\
\hline Speech & $72.5 \pm 27.51$ & $67.93 \pm 21.51$ & $58.33 \pm 14.43$ & 0.622 \\
\hline Shoulder & $82.5 \pm 20.58$ & $76.09 \pm 24.13$ & $50 \pm 43.3$ & 0.141 \\
\hline Taste & $85 \pm 17.48$ & $68.48 \pm 27.61$ & $50 \pm 43.3$ & 0.097 \\
\hline Saliva & $75 \pm 20.41$ & $53.8 \pm 37.63$ & $66.67 \pm 14.43$ & 0.207 \\
\hline Mood & $65 \pm 29.34$ & $60.33 \pm 26.13$ & $33.33 \pm 14.43$ & 0.189 \\
\hline Anxiety & $77.5 \pm 18.45$ & $80.98 \pm 17.63$ & $41.67 \pm 38.19$ & $0.004^{x}$ \\
\hline
\end{tabular}

TABLE 5: Comparison of Quality of Life Domains by Treatment Modalities

We also assessed the effect of follow-up duration on QOL scores in different domains. We observed that the scores for chewing, swallowing, taste, and appearance were the lowest in patients with a follow-up duration 


\section{Cureus}

of less than one year, while scores for speech, saliva, mood, and anxiety were highest in these patients. However, these differences in scores on the basis of follow-up duration were not statistically significant (Table 6).

\begin{tabular}{|c|c|c|c|c|}
\hline Domain & $\leq 1$ year $[n=9][$ Mean \pm SD] & $>1-2$ years $[n=16][$ Mean $\pm S D]$ & $>2$ years $[n=34][$ Mean \pm SD] & p-value \\
\hline Pain & $80.56 \pm 20.83$ & $78.13 \pm 20.16$ & $83.82 \pm 16.15$ & 0.649 \\
\hline Appearance & $58.33 \pm 25$ & $71.88 \pm 25.62$ & $79.41 \pm 25.72$ & 0.073 \\
\hline Activity & $61.11 \pm 22.05$ & $73.44 \pm 24.95$ & $65.44 \pm 28.88$ & 0.482 \\
\hline Recreation & $66.67 \pm 33.07$ & $79.69 \pm 33.19$ & $72.79 \pm 34.47$ & 0.436 \\
\hline Swallowing & $58.33 \pm 46.77$ & $60.94 \pm 41.8$ & $71.32 \pm 37.5$ & 0.651 \\
\hline Chewing & $22.22 \pm 36.32$ & $34.38 \pm 35.21$ & $45.59 \pm 37.67$ & 0.190 \\
\hline Speech & $83.33 \pm 21.65$ & $68.75 \pm 33.54$ & $75 \pm 26.83$ & 0.565 \\
\hline Shoulder & $69.44 \pm 34.86$ & $90.63 \pm 15.48$ & $77.21 \pm 29.75$ & 0.174 \\
\hline Taste & $52.78 \pm 42.29$ & $73.44 \pm 28.09$ & $74.26 \pm 35.08$ & 0.254 \\
\hline Saliva & $61.11 \pm 37.73$ & $53.13 \pm 41.71$ & $57.35 \pm 43.31$ & 0.899 \\
\hline Mood & $69.44 \pm 37.03$ & $59.38 \pm 30.1$ & $64.71 \pm 28.28$ & 0.604 \\
\hline Anxiety & $80.56 \pm 32.54$ & $79.69 \pm 29.18$ & $79.41 \pm 30.45$ & 0.987 \\
\hline
\end{tabular}

TABLE 6: Comparison of Quality of Life Domains by Follow-up Duration

When divided on the basis of patient's age, no significant difference of QOL scores was observed for any domain.

On HR-QOL and G-QOL scales, a majority of the patients responded as fair, good, very good or outstanding ( $88 \%$ and $91.5 \%$, respectively). Chewing and swallowing were the two major problems faced by the patients in the last seven days. Mood and anxiety were the least frequently described issues in our study group. More than half (57.6\%) of the patients did not experience any issues in the last seven days (Figure 2).

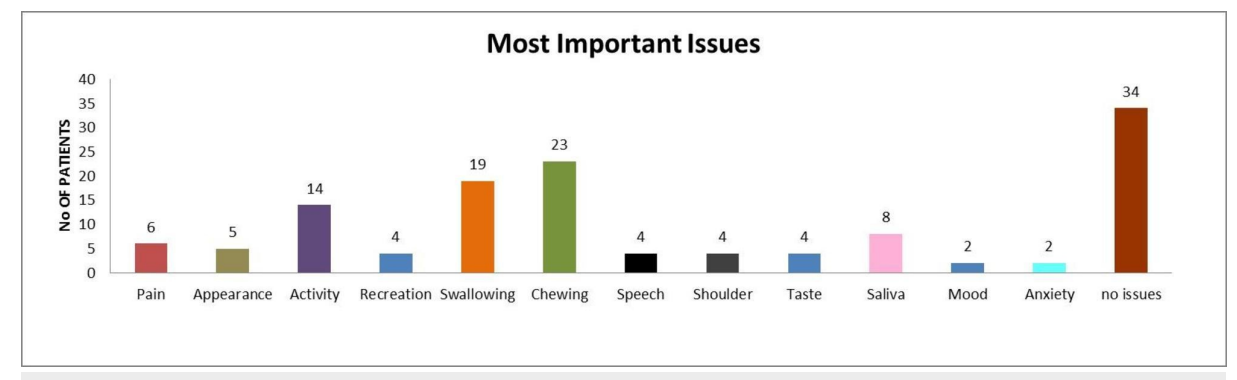

FIGURE 2: Most important issues experienced by patients in last seven days.

\section{Discussion}

The assessment of QOL is a complex issue involving the evaluation of different domains such as speech, pain, chewing, etc. As the outcome entails multiple factors, alternative study designs could include multivariate assessments of QOL domains. The UW-QOL questionnaire has already been validated by studies comparing the results of its application with those obtained from other well-established questionnaires in the same field of study. Besides effectively assessing QOL, the UW-QOL was well accepted by respondents and appraised as a reliable, practical, and low-cost instrument for surveying the functional status of patients with head and neck cancer [11]. However, the feasibility of its use in different languages still demands further research.

The salient feature of this study is that it highlights the factors affecting the QOL in post-operative OSCC 
patients. Few studies have described QOL issues in OSCC patients as a select group. Most often oral QOL issues are brought to the limelight as a subgroup of diverse head and neck cancers. Subsequently, issues related to OSCC are overwhelmed by general issues faced by head and neck cancer patients.

Male predominance seen in the participants of this study is in concordance with existing studies [12-19]. Mean patient's age in our study ( $47.9 \pm 12.7$ years) was younger than mean patients' age reported by several studies $[12-14,16,19]$. Male patients were slightly elder (mean \pm SD: $48.5 \pm 12.2$ years) than the female patients (mean \pm SD: $45.4 \pm 12.1$ years) but this difference was statistically insignificant $(\mathrm{p}=0.536)$.

The overall mean QOL score in our study was $68.2 \pm 24.7$ and it was lower than the mean QOL score $(74.6 \pm$ 18.2) of the study by Bhanja et al. [20]. Mean domain scores of each component were measured using UWQOL scale and the problems related to chewing (38.98 \pm 32.25$)$, saliva $(58.1 \pm 35.18)$, and $\operatorname{mood}(59.8 \pm 26.6)$ had minimum scores in our study. Similarly, in the study by Nagy et al. [14] and Andrade et al. [21], the major problem faced by the patients was also chewing. However, Rogers et al. [22] reported that $45 \%$ of patients in his study did not experience any chewing problem. Similarly, Bhanja et al. [20] also reported mood and anxiety as the major problems with mean values $46.5 \pm 23.7$ and $56.4 \pm 26.9$, respectively. These observations reinforce the importance of dental rehabilitation of patients subjected to surgical resection of OSCC. Speech impairment has been highlighted to be a concern for OSCC patients in some previous studies, but we observed good scores for speech in our study [11-14].

Overall mean composite QOL score of cheek tumor patients in our study (70.9 \pm 17.65$)$ was comparable to the mean QOL score of cheek tumor patients in the Bhanja et al. [20] study. Overall mean composite QOL score of patients with tongue tumors was significantly lower than scores of patients with cheek tumors in this study ( $p=0.029)$. The difference in scores of pain, swallowing, mood, and anxiety domains between these two groups can be explained by increased innervation and the critical role of tongue in swallowing.

Problems like chewing, swallowing, taste, saliva, appearance were experienced to a greater extent in latestage tumors and can be attributed to extensive surgery. In addition, these patients also receive adjuvant radiotherapy and/or chemotherapy which can cause fibrosis leading to difficulty in chewing, salivation, and disfigurement. Nausea, vomiting, weakness, and other side effects related to chemotherapy may also contribute to anxiety, mood disturbances, and lack of recreation in these patients receiving adjuvant treatment. This hypothesis is also favored by decreasing mean composite QOL scores with increasing modalities.

Patients with restricted mouth opening experienced more pain and difficulty in the speech which can be attributed to fibrosis and difficulty in mouth opening. Anxiety, lack of recreational activity, and the sense of poor appearance might partially be explained by the psychological impact of the disease.

Regarding HR-QOL and G-QOL, chewing, swallowing, activity, appearance, saliva, and pain were some of the important issues of patients in the last week before filling the questionnaire. These issues have also been highlighted in some of the previously reported studies [20-21].

Several studies have described the post-treatment evaluation of HR-QOL for OSCC patients and assessed factors associated with improvements in prognosis. These studies reinforce the hypothesis that patients who survived surgery may effectively improve and even recover their HR-QOL levels, at least to pre-operative ratings [11,14,19,23-24]. The improvement of certain QOL domain scores with increasing follow up duration, as seen in our study, points to the fact that cancer patients in the initial years of follow up experience psychological stress and post-treatment effects of different treatments they receive. These problems settle down with time and therefore, these patients need proper psychological counseling and support.

In the light of our findings, we think that patients with late-stage tumors and tongue tumors should be actively managed for pain. There should be special education and physical training for these patients to improve their mouth opening, chewing, speech, and swallowing. The use of liquid and semisolid diet in the initial post-operative period will also help in reducing these complaints. These patients should also get special counseling from a psychiatrist for their anxiety and mood problems.

Main limitations of this study are small sample size and single-center experience. In addition, self-reporting of the questionnaire by the patients bear the potential of over and/or underestimation. Multi-center studies on a larger cohort of patients are required to address the issues of postoperative QOL. Furthermore, prospective studies should be carried out to assess the role of interventions done to improve QOL.

\section{Conclusions}

Post-treatment QOL assessment of OSCC patients reveals a number of problems such as chewing, swallowing, saliva, lack of activity, mood disturbances, etc. Pre-operative clinical features including tumor site, tumor stage, and extent of mouth opening have a significant impact on post-treatment problems in different ways. Proper and timely interventions help in achieving better QOL levels early and closer to preoperative levels. 


\section{Additional Information \\ Disclosures}

Human subjects: Consent was obtained by all participants in this study. Patel Hospital issued approval 44. This study has been reviewed and granted approval form the Patel Hospital hospital ethics committee (approval number: 44). . Animal subjects: All authors have confirmed that this study did not involve animal subjects or tissue. Conflicts of interest: In compliance with the ICMJE uniform disclosure form, all authors declare the following: Payment/services info: All authors have declared that no financial support was received from any organization for the submitted work. Financial relationships: All authors have declared that they have no financial relationships at present or within the previous three years with any organizations that might have an interest in the submitted work. Other relationships: All authors have declared that there are no other relationships or activities that could appear to have influenced the submitted work.

\section{Acknowledgements}

I am Thankful to Bushra Ayub "Research officer" for providing me administrative and statistical and guiding me during the accomplishment of this research article.

\section{References}

1. Torre LA, Bray F, Siegel RL, Ferlay J, Lortet-Tieulent J, Jemal A: Global cancer statistics, 2012. CA Cancer J Clin. 2015, 65:87-108. 10.3322/caac.21262

2. Bhurgri Y: Cancer of the oral cavity - trends in Karachi South (1995-2002). Asian Pacific J Cancer Prev. 2005, 6:22-26.

3. Van der Waal, I: Are we able to reduce the mortality and morbidity of oral cancer: some considerations . Med Oral Patol Oral Cir Bucal. 2013, 18:33-37. 10.4317/medoral.18486

4. Morimata J, Otomaru T, Murase M, Haraguchi M, Sumita Y, Taniguchi H: Investigation of factor affecting health-related quality of life in head and neck cancer patients. Gerodontology. 2013, 30:194-200. 10.1111/j.1741-2358.2012.00662.x

5. Quinten C, Coens C, Mauer M, et al.: Baseline quality of life as a prognostic indicator of survival: a metaanalysis of individual patient data from EORTC clinical trials. Lancet Oncol. 2009, 10:865-871. 10.1016/S1470-2045(09)70200-1

6. Mücke T, Koschinski J, Wolff K-D, et al.: Quality of life after different oncologic interventions in head and neck cancer patients. J Craniomaxillofac Surg. 2015, 43:1895-1898. 10.1016/j.jcms.2015.08.005

7. Oskam IM, Verdonck-de Leeuw IM, Aaronson NK, et al.: Quality of life as predictor of survival: a prospective study on patients treated with combined surgery and radiotherapy for advanced oral and oropharyngeal cancer. Radiother Oncol. 2010, 97:258-262. 10.1016/j.radonc.2010.02.005

8. Djan R, Penington A: A systematic review of questionnaires to measure the impact of appearance on quality of life for head and neck cancer patients. J Plast Reconstr Aesthet Surg. 2013, 66:647-659. 10.1016/j.bjps.2013.01.007

9. Rogers SN, Gwanne S, Lowe D, Humphris G, Yueh B, Weymuller EA: The addition of mood and anxiety domains to the University of Washington quality of life scale. Head Neck. 2002, 24:521-529. 10.1002/hed.10106

10. Rogers SN, Lowe D, Yueh B, Weymuller EA Jr: The physical function and social-emotional function subscales of the University of Washington Quality of Life Questionnaire. Arch Otolaryngol Head Neck Surg. 2010, 136:352-357. 10.1001/archoto.2010.32

11. Dzebo S, Mahmutovic J, Erkocevic H: Quality of life of patients with oral cavity cancer . Mater Sociomed. 2017, 29:30-34. 10.5455/msm.2017.29.30-34

12. Hassan SJ, Weymuller EA Jr: Assessment of quality of life in head and neck cancer patients . Head Neck. 1993, 15:485-496. 10.1002/hed.2880150603

13. Gritz ER, Carmack CL, de Moor C, Coscarelli A, Schacherer CW, Meyers EG, Abemayor E: First year after head and neck cancer: quality of life. J Clin Onc. 1999, 17:352-360. 10.1200/JCO.1999.17.1.352

14. Nagy J, Braunitzer G, Antal M, Berkovits C, Novák P, Nagy K: Quality of life of head and neck cancer patients after tumor treatment and subsequent maxillofacial rehabilitation: an exploratory study. Qual Life Res. 2014, 23:135-143. 10.1007/s11136-013-0446-1

15. Hassanein KA-AM, Musgrove BT, Bradbury E: Psychological outcome of patients following treatment of oral cancer and its relation with functional status and coping mechanisms. J Craniomaxillofac Sur. 2005, 33:404409. 10.1016/j.jcms.2005.05.005

16. Tang JAL, Rieger JM, Wolfaardt JF: A review of functional outcomes related to prosthetic treatment after maxillary and mandibular reconstruction in patients with head and neck cancer. Int J Prosthodont. 2008, 21:337-354.

17. Lopez JH, Mayordomo AR, Rosado RL, Fernandez CIS, Gallana S: Quality of life in long-term oral cancer survivors: a comparison with Spanish general population norms. J Oral Maxillofac Surg. 2009, 67:1607-1614. 10.1016/j.joms.2008.12.039

18. Kim TW, Youm H-Y, Byun H, Son Y-I, Baek C-H: Treatment outcomes and quality of life in oropharyngeal cancer after surgery-based versus radiation-based treatment. Clin Exp Otorhinolaryng. 2010, 3:153-160. 10.3342/ceo.2010.3.3.153

19. Nazar G, Garmendia ML, Royer M, McDowell JA, Weymuller EA Jr, Yueh B: Spanish validation of the University of Washington Quality of Life questionnaire for head and neck cancer patients. Otolaryng Head Neck Surg. 2010, 143:801-807. 10.1016/j.otohns.2010.08.008

20. Bhanja A, Roy C, Poddar R, Poddar RN: Quality of life in oral cancer patients following pectoralis major 


\section{Cureus}

myocutaneous flap reconstruction. Int JCMR. 2016, 3:1366-1371.

21. Andrade FPd, Antunes JLF, Durazzo MD: Evaluation of the quality of life of patients with oral cancer in Brazil. Braz Oral Res. 2006, 20:290-296. 10.1590/S1806-83242006000400002

22. Rogers SN, Hannah L, Lowe D, Magennis P: Quality of life 5-10 years after primary surgery for oral and oropharyngeal cancer. J Craniomaxillofac Surg. 1999, 27:187-191.

23. Pinjatela R: Some characteristics of the quality of life of people with or without malignant illness . Croatian Rev Rehab Res. 2008, 44:79-98.

24. Villaret AB, Cappiello J, Piazza C, Pedruzzi B, Nicolai P: Quality of life in patients treated for cancer of the oral cavity requiring reconstruction: a prospective study. Acta Otorhinolaryngol Ital. 2008, 28:120-125. 